\title{
Application of Risk Informed Decision Making to Highly Reliable Three Dimensionally Woven Thermal Protection System for Mars Sample Return
}

\author{
J. Needels ${ }^{1}$ and P. Gage ${ }^{2}$ \\ Neerim Corporation, NASA Research Park, Moffett Field, CA, 94035, USA \\ D. Ellerby ${ }^{3}$, E. Venkatapathy ${ }^{4}$, K. Peterson ${ }^{5}$ J. Vander Kam ${ }^{6}$
}

Exploration Technology Division, NASA Ames Research Center, Moffett Field, CA, 94035, USA

The NASA Risk Informed Decision Making process is used to ass ess a trade space of three dimensionally woven thermal protection systems for application to the Mars Sample Return Earth Entry Vehicle. Candidate architectures are assessed based on mission assurance, technical development, cost, and schedule risk. Assessment methodology differed between the architectures, utilizing a four-point quantitative scale for mission assurance and technical development and highly tailoredPERT techniques for cos tand schedule. Risk results are presented, in addition to a review of RIDM effectiveness for this application.

\section{Nomenclature}

$\begin{array}{ll}C P M & =\text { Critical Path Methods } \\ E E V & =\text { Earth Entry Vehicle } \\ H E E E T & =\text { Heatshield for Extreme Entry Environments Technology } \\ I L & =\text { Insulating Layer } \\ M S R & =\text { Mars Sample Return } \\ P E R T & =\text { ProgramEvaluation and Review Technique } \\ R I D M & =\text { Risk Informed Decision Making } \\ R L & =\text { Recession Layer }\end{array}$

\section{Introduction}

Due to the possibility of inadvertent release of biological samples, the Mars Sample Return (MSR) Earth Entry Vehicle (EEV) is expected to carry unprecedented requirements for planetary protection. These requirements flow down to all sub-systems, including the thermal protection system(TPS).

Accurate characterization of mis sion risk is necessary to support certification against requirements. NASA provides handbook guidance for Risk Informed Decision Making (RIDM), a deliberative decision-making process employed for major architecture and design decisions involving high stakes and complexity [1] [2]. The large TPS trade space coupled with a lack of quantitative risk data make MSR EEV TPS selection an excellent candidate for RIDM application.

\footnotetext{
${ }^{1}$ Systems Engineer, NeerimCorporation, AIAA Student Member.

${ }^{2}$ Principal Engineer, Neerim Corporation, AIAA Associate Fellow.
} 
As part of a preliminary risk characterization conducted under a NASA Ames IRAD activity, the RIDM process was applied to a trade space of three dimensionally (3D) woven TPS variants being considered for MSR, though the methodology developed is applicable to the larger architectural trade that includes TPS options that are not 3D-woven.

The paper begins with an outline of the RIDM process, followed by a summary of the 3D woven variants considered for MSR. The risk as sessment methodology is then summarized, followed by presentation of theresults of the risk as sessment activity. The paper concludes with an assessment of RIDM effectiveness for this application and a pers pective on the utility of RIDM application more generally.

\section{Risked Informed Decision Making (RIDM)}

In the absence of uncertainty, decision making reduces to a determinis tic multi-disciplinary optimization process, which consists of selecting froma trade space theoption that best satisfies mission requirements. However, given the realities of finite testing, data and operational experience, uncertainty is an inherent as pect of the decision-making process.

Uncertainty in decision-making is significant when it results in degraded performance with res pect to one or more system performance objectives. Risk, resulting from the uncertainty as sociated with one or more performance objectives, can be defined operationally as a setof three components [1]:

- The Scenario(s) leading to degraded performance with respect to one or more performance measures

- The Likelihood(s) or probability (quantitative or qualitative) of those scenarios

- The Consequence(s) (quantitative or qualitative severity of performance degradation) that would result if those scenarios were to occur

Risk Informed Decision Making (RIDM) is a deliberative process that uses information about ris k to guide major architecture and design decis ions. RIDM provides a framework to au gment quantitative data with subject matter expert (SME) technical opinion in order to make a robust decision by considering all sources of mission risk [1].

\section{Three-Dimensionally Woven TPS}

Three-dimensional weaving employs interconnections between layers that provide high interlaminar strength, in contrast with conventional structural composites that rely on resin to hold 2D plies together. This strength in the through-thickness direction should mitig ate mechanical loss of char when the surface of the TPS is exposed to extreme heating and mitigate the generation of in-plane cracks due to high temperature gradients. Figure 1 provides a schematic of a generic three-dimen sional weave, with different fiber ty pes used at different locations, and varying weave density at different layers through the thickness. Material properties such as conductivity and strength can be tailored through selection of fiber ty pe and weave pattern, to deliver an efficient TPS tailored for specific miss ion needs. For an ablative TPS (i.e. a system that sacrifices mas s to accommodatehigh heating rates), it is at tractive to partition the material into a region that ablates, or recedes, (the Recession Layer (RL)) and a region that ins ulates the underlying structure from the incident heating (the Insulating Layer (IL)). The mechanical interlock between layers provides an unprecedented opportunity for tailoring of the TPS in this manner.

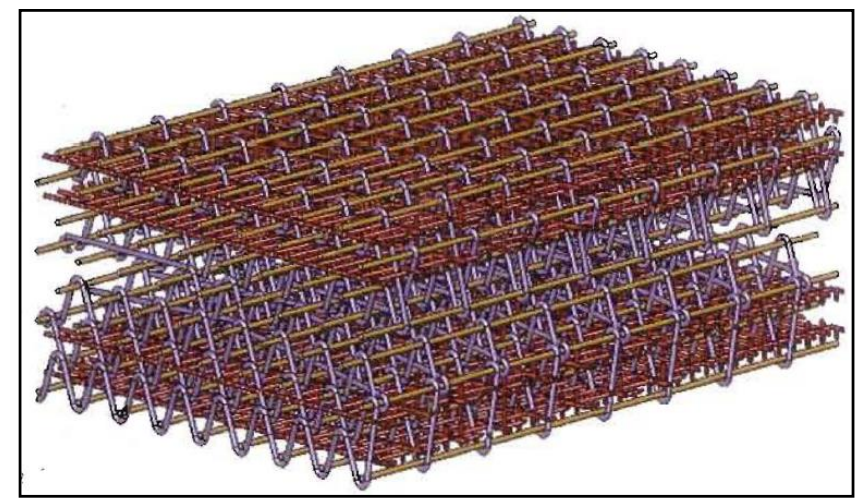

Figure 1. Schematic of generic three-dimens ionally woven material [3]. 
The size of a woven part is limited by the number of yarns that can be controlled by a loom: warp yarns are raised and lowered by hooks attached to the loomhead, and fillyarns are ins erted between the raised and lowered yams. The weave pattern is defined by the different sets of raised yarns for each insertion of a fill yarn.

Using fine (low diameter) yarns reduces the volume of material delivered for a given number of yarns. A large thickness reduces the width that can be delivered by a given number of hooks. While it is attractive to make a complete heatshield froma single woven piece, restrictions on yarn diameter and requirements for large thickn ess may require as sembly of several woven tiles, particularly if the heatshield is large (diameter exceeds width of material off the loom).

The dry woven material is commonly infused with phenolic to enhance its thermal protection performance [4]. The material is typically formed to near-final shape prior to infusion, which rigidizes it, and then machined to match the contour of the substrate. The amount of infusion (density of phenolic in the final part) can be adjusted to trade thermal performance against convenience of integration.

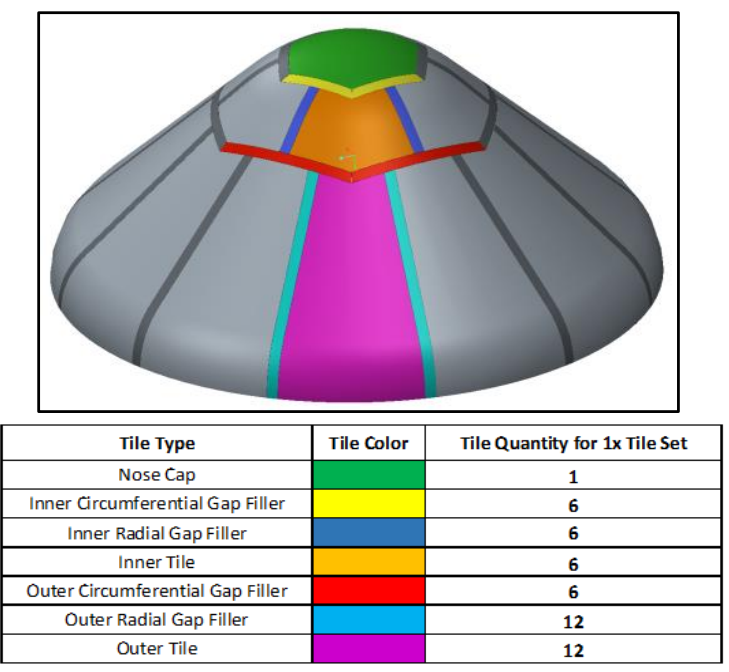

Figure 2. HEEET engineering test unit has demons trated manufacturing and integration at 1 -meter scale [3].

The woven material can be integrated into a complete heatshield in a number of ways. Seven different 3D woven variants have been considered as part of the study, as described below:

\section{A. Heatshieldfor Extreme Entry Environments Technology (HEEET)}

A dual layer, tiled TPS, consisting of a high density, all carbon upper layer to manage recession and a lower density, carbon-phenolic yarn insulation layer to manage heat transfer to the entry vehicle structure. The weave is infused using phenolic resin and machined into tiles, as illus trated in Figure 2.

\section{B. HEEET 6k Recession Layer}

A variant of HEEET that is woven with a $6 \mathrm{k}$ recession layer (6000 fibers per bundle) instead of the nominal $3 \mathrm{k}$ tow (3000 fibers perbundle), resulting in a coarser weave.

\section{Insulation Layer Only Tiled}

A tiled architecture consisting of only the lower density HEEET ins ulation layer.

\section{3D Woven Single Piece}

An architecture consisting of the same dual-layer structure as HEEET, but manufactured and attached to the vehicle as a single piece.

\section{E Dry Woven SinglePiece}

A variant of 3D woven single piece that retains the dual-layer structure of HEEET but without phenolic impregnation. 


\section{F. Insulating Layer Only Single Piece}

A variant of 3D woven single piece consisting of only the HEEET insulation layer, infused with phenolic resin.

\section{G. 3D Carbon-Carbon}

A single-piece, hot-structure architecture, with a nominal composition similar to a carbonized HEEET recession layer.

\section{Risk Assessment Methodology}

Four categories of risk were identified for 3D woven TPS: mis sion assurance, technical development, cost, and schedule. Mission assurance addresses sources of residual risk that may res ult in failure during the mis sion. Technical development addresses the possibility that planned technical capability may not mature due to unforeseen technical deficiencies, or that capability cannot be verified to the certification levels required by the mis sion. Even if technology is capable of being matured to deliver adequate mis sion performance, there is risk that the resource demand will be unacceptable. Hence cost and schedule risk are als o evaluated. Illustrations of theserisk categories is given in Figure 3 below.

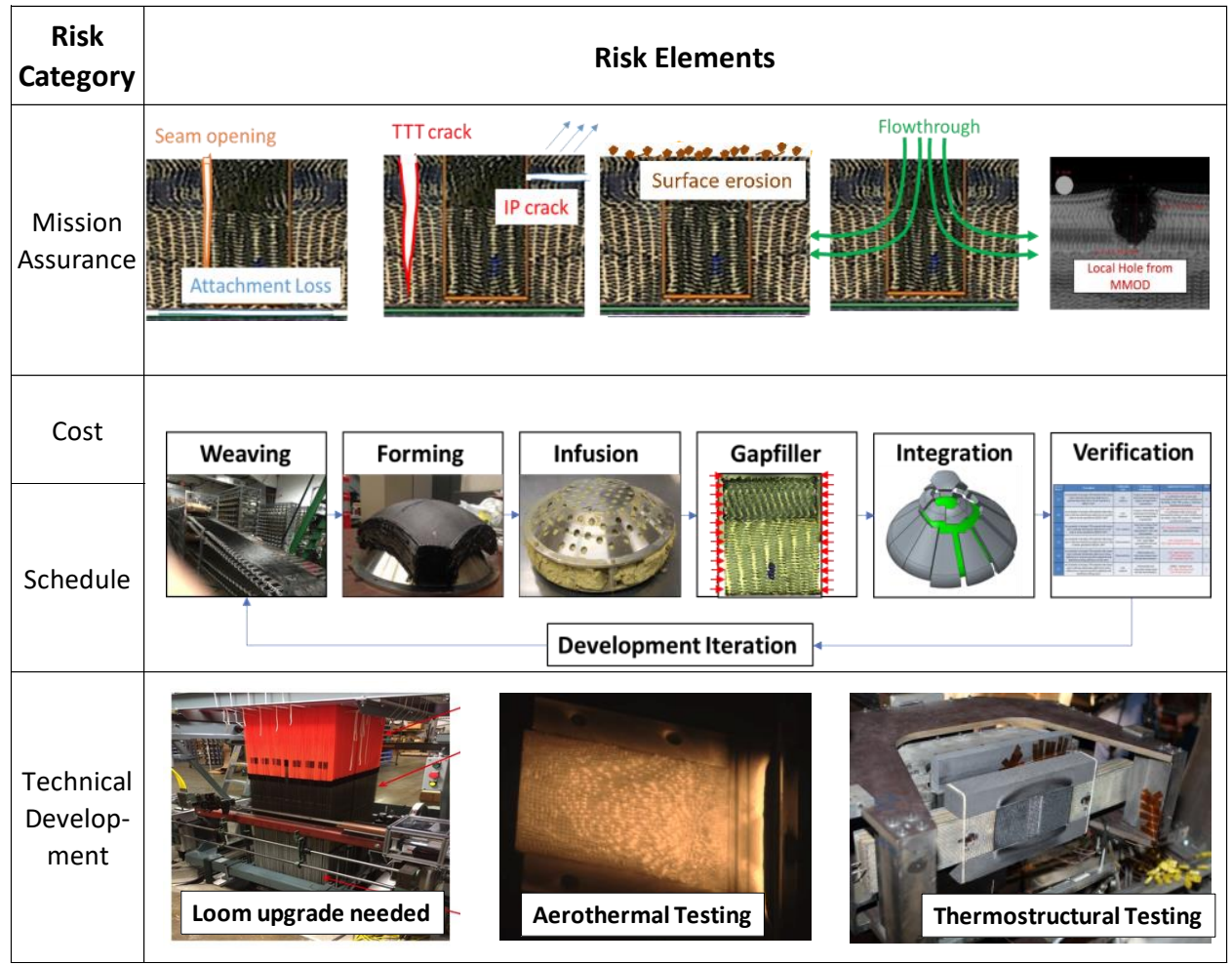

Figure 3. Summary of Risk Elements

Assessment methodology differed between the risk categories. For mis sion as surance and technical development, a four-point quantitative scale was developed to capture both the risk and uncertainty associated with each selection in the trade s pace. A description of the ranking s cale is given in Table Ibelow.

Table I. Mission Assuranceand Technical Development Scoring Scale

\begin{tabular}{|c|c|}
\hline \multicolumn{2}{|c|}{ Rating Scale } \\
\hline 0 & Inadequate \\
\hline 1 & Marginal \\
\hline 2 & Adequate Margins \\
\hline 3 & No Credible Risk \\
\hline
\end{tabular}


0 - Inadequate

The option is known to have sub-marginal or unacceptable performance.

1 - Marginal

Either the option is known to have marginal performance, or there is sufficient uncertainty that performance cannot be characterized as having adequate margins within a reas onable degree of certainty.

2 - Adequate Margins

The option has demonstrated adequate performance, within accepted margins.

3 - No Credible Risk

The option demonstrates no credible risk of failing to meet the performance objective. Either the risk does not apply to the option considered, or performance data shows no credible way in which the option could fail to meet the performance objective.

A highly tailored Program Evaluation and Review Technique (PERT) was employed to perform a quantitative analysis of cost and schedule risk for a sample of the 3D woven trade space. Data was gathered from program development experience (particularly the HEEET engineering test unit (ETU) development), contractor estimates, and subject matter expert technical opinion. Estimated cost/schedule values and uncertainties were developed for each process, and the results were used to generate total estimates and uncertainties along the critical path. Accurate characterization of uncertainty in SME data was made difficult by the low information state at the time of analysis. The objective of these uncertainty estimates is to provide a cursory estimate of the relative risk to dis criminate between alternatives. Uncertainty estimates provide approximate bounds on cost and schedule for each item analyzed at a reas onable confidence level.

\section{Risk Assessment Results}

Results for the four risk categories described above are summarized below:

\section{A. Mission Assurance}

A matrix showing risk levels for the mission assurance risk candidates is in Table II below.

Table II. Mission Assurance Risk Assessment Results

\begin{tabular}{|c|c|c|c|c|c|c|c|c|}
\hline \multirow{2}{*}{\multicolumn{2}{|c|}{ Risk }} & \multicolumn{7}{|c|}{ Trade Space } \\
\hline & & HEEET & $\begin{array}{c}\text { 6K } \\
\text { Recession } \\
\text { Layer Tiled }\end{array}$ & $\begin{array}{l}\text { Insulating } \\
\text { Layer Only } \\
\text { Tiled }\end{array}$ & $\begin{array}{c}\text { 3D Woven } \\
\text { Single } \\
\text { Piece }\end{array}$ & $\begin{array}{c}\text { Dry } \\
\text { Woven } \\
\text { Single } \\
\text { Piece }\end{array}$ & \begin{tabular}{|c} 
Insulating \\
Layer Only \\
Single \\
Piece
\end{tabular} & $\begin{array}{l}3 \text { 3D C-C } \\
\text { Single } \\
\text { Piece }\end{array}$ \\
\hline \multicolumn{2}{|c|}{ Mission Assurance } & & & & & & & \\
\hline Failure Mode & Load Case & & & & & & & \\
\hline Local Hole & $\begin{array}{l}\text { MMOD, Shock, } \\
\text { Integration }\end{array}$ & 2 & 2 & 1 & 2 & 1 & 1 & 1 \\
\hline $\begin{array}{l}\text { Surface Erosion } \\
\text { (Mechanical) }\end{array}$ & Entry & 2 & 1 & 1 & 3 & 1 & 1 & 3 \\
\hline Seam Opening & Cold Soak, Entry & 2 & 1 & 2 & 3 & 3 & 3 & 3 \\
\hline Flow Through & Entry & 2 & 2 & 1 & 3 & 1 & 2 & 3 \\
\hline Cracking & Cold Soak, Shock & 3 & 3 & 3 & 3 & 3 & 3 & 3 \\
\hline Attachment Failure & Cold Soak, Entry & 2 & 2 & 2 & 2 & 2 & 2 & 1 \\
\hline Shape Stability & Entry & 2 & 2 & 2 & 2 & 2 & 2 & 1 \\
\hline
\end{tabular}


In the left hand column of the table are the failure modes associated with mis sion assurance risk, along with their as sociated load cases. The TPS ranking against the associated risks are organized in columns, with comments on the scoring given at right. 3D woven single piece has thehighest aggregate score with res pect to mis sion assurance.

\section{B. Technical Development}

Technical development risks are summarized below in a similar fashion.

Table III. Technical Development Risk Results

\begin{tabular}{|c|c|c|c|c|c|c|c|}
\hline \multirow[b]{2}{*}{ Risk } & \multicolumn{7}{|c|}{ Trade Space } \\
\hline & HEEET & \begin{tabular}{|c|}
$6 \mathrm{KK}$ \\
Recession \\
Layer Tiled
\end{tabular} & $\begin{array}{c}\text { Insulating } \\
\text { Layer Only } \\
\text { Tiled }\end{array}$ & $\begin{array}{c}\text { 3D Woven } \\
\text { Single } \\
\text { Piece }\end{array}$ & $\begin{array}{c}\text { Dry } \\
\text { Woven } \\
\text { Single } \\
\text { Piece }\end{array}$ & $\begin{array}{c}\text { Insulating } \\
\text { Layer Only } \\
\text { Single } \\
\text { Piece }\end{array}$ & $\begin{array}{c}\text { 3D C-C } \\
\text { Single } \\
\text { Piece }\end{array}$ \\
\hline \multicolumn{8}{|l|}{ Technical Development } \\
\hline Weaving 60" Width & 3 & 3 & 3 & 1 & 1 & 2 & 1 \\
\hline Areal Property Variation in Formed Part & 3 & 3 & 3 & 2 & 2 & 2 & 1 \\
\hline Attachment to Substrate & 2 & 2 & 2 & 2 & 2 & 2 & 1 \\
\hline Certifiability & 1 & 1 & 1 & 2 & 2 & 2 & 1 \\
\hline
\end{tabular}

The four technical development risks assessed are given at right. The three tiled architectures share the maximum score for technical development, butcarry marginal performance with respect to certifiability. 


\section{Cost}

Analysis of system cost was conducted on a representative sample of the 3D woven trade space. Results for HEEET, 3D Woven Single Piece, and Insulating Layer Only Single Piece are given in Table IV below.

Table IV. Relative Cost Comparis on

\begin{tabular}{|c|c|c|c|c|c|c|c|}
\hline \multicolumn{2}{|c|}{ System Cost } & \multicolumn{2}{|c|}{ HEEET MSR } & \multicolumn{2}{|c|}{ 3D Woven Single Piece } & \multicolumn{2}{|c|}{$\begin{array}{c}\text { Ins ulating Layer Only } \\
\text { Single Piece }\end{array}$} \\
\hline $\begin{array}{c}\text { Cost } \\
\text { Categories }\end{array}$ & Detail & $\begin{array}{c}\text { Cost } \\
\text { (Norma- } \\
\text { lized } \\
\text { Relative } \\
\text { to } \\
\text { Baseline } \\
\text { HEEET) } \\
\end{array}$ & $\begin{array}{c}\text { Uncertainty } \\
\quad( \pm)\end{array}$ & $\begin{array}{c}\text { Cost } \\
\text { (Norma- } \\
\text { lized } \\
\text { Relative } \\
\text { to } \\
\text { Baseline } \\
\text { HEEET) }\end{array}$ & $\begin{array}{c}\text { Uncertainty } \\
( \pm)\end{array}$ & $\begin{array}{c}\text { Cost } \\
\text { (Norma- } \\
\text { lized } \\
\text { Relative } \\
\text { to } \\
\text { Baseline } \\
\text { HEFET) }\end{array}$ & $\begin{array}{c}\text { Uncertainty } \\
( \pm)\end{array}$ \\
\hline \multirow{4}{*}{ Dev.Cost } & Weave Dev. & 0 & - & 4 & 2 & 4 & 2 \\
\hline & Design & 1 & - & 2 & 1 & 2 & 1 \\
\hline & $\begin{array}{l}\text { Components } \\
+ \text { Integration } \\
\end{array}$ & 2.5 & - & 2.5 & - & 2.5 & - \\
\hline & Testing & 5 & 1 & 4 & 1 & 4 & 1 \\
\hline \multirow{3}{*}{$\begin{array}{l}\text { Mfg. and } \\
\text { Integration }\end{array}$} & Weave & \multirow{3}{*}{12} & \multirow{3}{*}{2} & \multirow{3}{*}{6} & \multirow{3}{*}{2} & \multirow{3}{*}{6} & \multirow{3}{*}{2} \\
\hline & $\begin{array}{l}\text { Forming + } \\
\text { Infusion + } \\
\text { Machining }\end{array}$ & & & & & & \\
\hline & $\begin{array}{c}\text { Carrier }+ \\
\text { Integration }\end{array}$ & & & & & & \\
\hline \multicolumn{2}{|c|}{ Property Testing } & 0 & - & 1 & - & 1 & - \\
\hline \multicolumn{2}{|c|}{ Certification } & 10 & 3 & 5 & 2 & 5 & 2 \\
\hline \multicolumn{2}{|c|}{ Documentation } & 0 & - & 0 & - & 0 & - \\
\hline \multicolumn{2}{|c|}{$\begin{array}{c}\text { Project Mgmt. + Systems } \\
\text { Eng. }\end{array}$} & 6 & - & 5 & - & 5 & - \\
\hline \multicolumn{2}{|c|}{ Total } & 36.5 & 6 & 29.5 & 8 & 29.5 & 8 \\
\hline
\end{tabular}

Cost values and uncertainties were developed relative to baseline HEEET, specifically leveraging SMEexperience with HEEET ETU development, construction, and testing. Based on these preliminary results, HEEET adaptation for MSR would be more expensive than a single piece configuration, but with a lower cost uncertainty. However, this list of cost categories may not be exhaustive, and additional input on cost categories and risks is necessary to make a robustdecision.

\section{Schedule}

A schedule for each option inclu des all steps as sociated with technical development, production, and certification through the flight readiness review (FRR). An accepted method for analyzing schedule risk is Critical Path Methods (CPM). CPM involve identifying the critical path, or the longest mean path through a schedule network, and treating it as the schedule risk driver. This is not always a valid as sumption, as variation in the actual event duration during the project can result in changes to the critical path. A comprehensive Monte Carlo analy sis can capture the effect of critical path changes in different schedule in stances, but such analy sis is beyond the scope of the current study.

Es timates for the duration and uncertainty of each event are collected fromSMEs and/or relev ant contractors. Several methods for this exist, including collecting best-case, worst-case, and most-likely es timates for each event, then using these values to construct a Normal dis tribution of possible durations. In this case, SMEestimates were collected for each option with SMEestimated uncertainties for only a subset of events. The res ults comparing HEEET with a single piece 3D woven are shown in Table V below. 
Table V. Relative Schedule Comparis on

\begin{tabular}{|c|c|c|c|c|c|}
\hline \multicolumn{3}{|c|}{ HEEET } & \multicolumn{3}{|c|}{ 3D Woven Single Piece } \\
\hline Event Description & $\begin{array}{c}\text { Time } \\
\text { (months) }\end{array}$ & $\begin{array}{c}\text { Uncertainty } \\
\text { (months) }\end{array}$ & Event Description & $\begin{array}{c}\text { Time } \\
\text { (months) }\end{array}$ & $\begin{array}{l}\text { Uncertainty } \\
\text { (months) }\end{array}$ \\
\hline Weave Procurement & 6 & - & Weave Procurement & 6 & - \\
\hline $\begin{array}{c}\text { Raw Material } \\
\text { Purchase/Processing, } \\
\text { Loom Startup and } \\
\text { Verification }\end{array}$ & 7 & 1 & $\begin{array}{l}\text { Loom Development } \\
\text { (from construction } \\
\text { to startup and } \\
\text { verification) }\end{array}$ & 24 & 6 \\
\hline $\begin{array}{l}\text { Time to weave ESH } \\
\text { Dev Coupons, } \\
\text { MDU, and flight } \\
\text { material }\end{array}$ & 9 & 2.25 & $\begin{array}{c}\text { Time to weave flight } \\
\text { material (no } \\
\text { MDU/ESH) }\end{array}$ & 3 & 0.75 \\
\hline $\begin{array}{l}\text { Form last batch of } \\
\text { flight material }\end{array}$ & 1 & - & Form flight material & 3 & - \\
\hline $\begin{array}{l}\text { Infuse last batch of } \\
\text { flight material }\end{array}$ & 1.5 & 0.5 & $\begin{array}{c}\text { Infuse flight } \\
\text { material }\end{array}$ & 2 & 0.5 \\
\hline $\begin{array}{l}\text { Machine last batch } \\
\text { of flight material }\end{array}$ & 4 & - & $\begin{array}{l}\text { Machine flight } \\
\text { material }\end{array}$ & 2 & - \\
\hline Integration & 6 & - & Integration & 1 & - \\
\hline CT Scan & 2 & 1 & CT Scan & 1 & 1 \\
\hline Certification & 6 & 3 & Certification & 6 & 3 \\
\hline Total & 42.5 & 7.75 & Total & 48 & 11.25 \\
\hline
\end{tabular}

Since a firm mis sion timeline has not been established, the emphasis of the analysis is on event duration. From the analys is it is evident that a 3D woven single piece carries both a longer total duration, as well as larger schedule uncertainty, relative to the tiled baseline. However, if multiple units are needed, advantage quickly shifts to the single piece. For three units or more, assuming that integration is performed serially, the single piece would have a lower mean critical path as compared to the tiled architecture.

\section{Conclusion}

A risk analysis framework has been developed that employs the RIDM process to as sess relative risk between different 3D woven TPS alternatives for MSR EEV. RIDM was utilized due to the high stakes associated with TPS architecture selection and the scarcity of quantitative performance data for the 3D woven variants. RIDM provides a framework to elicit SME estimates of performance for elements of the trade space, based on experience with HEEET program development. In some cases, the process confirmed expectations regarding system performance. However, in other cas es the formal procedures of RIDM process brought to light surprising results. For example, the perceived certifiability benefits to cost and schedule for a single piece architecture did not show up for a single mis sion, due to non-recurring engineering development constituting a significant fraction of mis sion resource allocation.

The main difficulty in applying RIDM is uncertainty quantification for problems with a low information state, due to the conservatively high uncertainties that are predicted. SMEestimates gathered as part of this study have variance that exceeds the mean difference between alternatives for cost and schedule risk. Des pite this limitation, which is probably common at the conceptual design phase, the RIDM process provides a u seful formal framework for guiding risk discussion forhigh level design decisions. As the scope of the trade space is decreased, programrequirements are refined, and additional data becomes available, increasingly quantitative analy sis tools can be employed to support more accurate estimation and uncertainty characterization. 


\section{References}

[1] Dezfuli, H, et al, NASA Risked Informed Decision Making Handbook, Washington, DC: Office of Safety and Mission Assurance, 2010.

[2] Dezfuli, H, et al, NASA Risk Management Handbook, Washingt on, DC: Office of Safety and Mission Assurance, 2011.

[3] Gage, P. J., et al, "Overview of Heatshield for Extreme Entry Environments," URL: https://discovery.larc.nasa.gov/discovery/pdf files/25 HEEET Technology Overview (HEEET-1002).pdf.

[4] Tran, H. K., Henlines, W. D., Hsu, M. -t. s., Rasky, D. J., Riccitiello, S. R., NASA Ames Research Center, Moffett Field, CA, U.S. Patent Application for "Low-density resin impregnated ceramci article having an average density of 0.15 to $0.40 \mathrm{~g} / \mathrm{cc} "$ United States of America Patent 5,536,562, 14 March 1994.

[5] Needels, J., and Gage, P. J., Technical Basisfor Deliberation: Highly Reliable $3 D$ Woven Thermal Protection System for Mars Sample Return, 2018.

[5] NPR 8000.4B Agency Risk Management Procedural Requirements, National Aeronautics and Space Administration, Washington, DC, 2017. 